\title{
Algunas reflexiones sobre el derecho penal de nuestro tiempo*
}

\section{Some Reflections on the Criminal Law of Our Time}

Fecha de recepción: 20 de abril de 2010 Fecha de aprobación: 31 de mayo de 2010

\author{
Jorge Enrique Valencia Martínez**
}

\section{Resumen}

En el presente ensayo encontramos un análisis y una valoración a la realidad del derecho penal en nuestro tiempo. Se estudian los conceptos jurídicos, la jurisprudencia y el papel que juegan quienes deben interpretar la ley, en el marco de un delicado contexto político y social por el cual atraviesa nuestro país.

Palabras clave

Derecho penal, realidad, jurisprudencia penal.

- Artículo de Reflexión que se incorpora al módulo de Derecho Penal, Facultad de Derecho de la Universidad Santo Tomás.

* Docente de la Facultad de Derecho de la Universidad Santo Tomás. Exmagistrado de la Corte Suprema de Justicia. 


\section{Abstract}

This text is an essay that reflects and appreciates the reality of criminal law in our times. It examines the legal concepts, jurisprudence and the role of those who must interpret the law as part of a delicate political and social context in which our country is facing.

\section{Key words}

Criminal law, indeed, criminal jurisprudence.

\section{INTRODUCCIÓN}

El proceso penal que lleva a cabo la Sala Penal de la Corte Suprema de Justicia en contra de algunos miembros del Congreso colombiano -no necesito subrayarlo o ponerlo en relieve, que él solo se destaca-, es acaso, uno de los dos o tres más importantes de los últimos cien años. No hay cuestión que haya suscitado más interés público que este proceso y lejos está de haberse agotado sus efectos. En un terreno que es suyo, y sin que hubiera faltado el aparato mediático y la reacción callejera, la Corte ha dado su veredicto con autos de detención y llamamientos a juicio, $y$, por supuesto, con otras tantas condenas, y esto es respetable. Su influencia sigue latente y todos se rinden con lenguaje intransigente y acomodado a las decisiones judiciales, sin que falten la adulación y la reverencia, que entre nosotros son más que familiares. Para algunos, y es posible, ahí está encerrada toda la juridicidad, y la ciencia penal del derecho colombiano, y la pura técnica dogmática, y los profundos conocimientos de nuestra disciplina ${ }^{3}$, bien que otros, aunque no

3 Este punto necesita ser resaltado -apuntaba el profesor Dalmo de Abreu Dallari, Decano de la Facultad de Derecho de la Universidad de San Pablo-, porque por una serie de razones, la magistratura se envuelve en un aura de sacralidad, los jueces adquieren una imagen de seres perfectos, superiores a todos los mortales y especialmente iluminados, merecedores de un respeto semejante a la veneración religiosa. Eso, por un lado, trajo perjuicios a toda la sociedad, porque retardó el reconocimiento de las fallas que la magistratura, como organización humana y sujeta a presiones de muchos intereses, mantuvo a través del tiempo. Por otro lado, los propios magistrados acabaron siendo víctimas de esa superestimación, lo digan -porque tienen sus secretos y rincones-, crean lo contrario, lo cual también posee su valor. Y es que en los hombres hay pasiones y flaquezas, ni más, ni menos, para decir las cosas que nos envuelven, con calma, con la calma necesaria para emitir juicios teñidos de diversos colores, con visión oscura o despejada, según los términos contrapuestos de la cuestión. Con las consideraciones debidas y mi sincera confesión pienso que es la posteridad, en su continua frustración, la que debe confirmar aquel fallo 0 votar en contra. Por cierto que soy de la opinión -y hablo como si fuera magistrado todavía-, que no es mérito de la justicia penal, atisbar el sol de los muertos, ni desconocer el derecho de defen$\mathrm{sa}$, ni orillar los principios del debido proceso, que es tanto como decir, lo sombrío. Que los fantasmas vuelven mañana cuando fríamente se juzgue la época en que se vivió.

Siento la necesidad de decir, con fuerza y con toda lealtad, que en el proceso se escribieron páginas de muy controvertida juridicidad, cuyo relieve se acusa más y más, con la lectura de los folios. No importa que esté aislado en esta batalla y que únicamente me acompañen, en mi soledad mental, una modes. ta autoridad y una firme convicción. Mejor, porque así no claudico. Con unos argumentos agotadores y a los extremos límites del esfuerzo intelectual,

pues ni siquiera se admitía que se hablara públicamente de sus necesidades humanas y profesionales (La independencia de jueces y abogados en Argentina, Brasil, Paraguay y Uruguay Editorial M. B. A., Montevideo, 1988, pp. 23-24). 
como fácilmente se puede comprobar, la defensa que me confió. Mostró a la Corte muy sensibles yerros dogmáticos y probatorios que inmediatamente se desestimaron, si a mano viene, porque no acerté en su examen, o porque no me hice entender, o por las dos cosas juntas, que todo tiene su explicación. Aspiraba, con la razón jurídica -que en mi caso ha tenido vida intensa y muy agitada-, hacer patentes los problemas esenciales del expediente donde actué en su justo contenido y en su exacta dimensión. No lo conseguí, bien que sigo y seguiré entendiendo que la lógica del Derecho penal, con todo orden y verdad, no es lógica formal, sino una lógica viva que vive con hechos, acontecimientos y otras mil realidades, que son casi, su alimento natural, su cuenta y razón ${ }^{4}$.

Creo que a la luz de los sucesos y ante los elementos de juicio y de ciencia que se conocieron debió examinarse la realidad y la doctrina jurídica del

4 Alguna vez escribí -recordando a los mejores autores que se ocuparon de estos temas-, que la rebelión y la sedición y los restantes comportamientos que atentan contra el régimen constitucional y legal del Estado, son delitos políticos por excelencia. Tajantemente expresé, citándolos, que, "ante la realidad de la delincuencia política y de los hechos cumplidos, los prejuicios son muchos. Pasando adelante, el triunfo de la revolución impide que los fallos del derecho penal lleguen a ella como consecuencia de la victoria, sin que nadie rompa una lanza por defender el régimen del gobierno anterior. Los rebeldes y conspiradores pasarán a ser los personajes del nuevo orden, y serán promovidos a los altos cargos y destinos del Estado. Por lo que mira al fracaso de la rebelión, páginas penetrantes de enjuiciamiento histórico-político se harán, condenando a los disidentes como criminales, y sobre los cuales caerá, haciendo el mayor aoravio, el castigo y la represión, sin que nada ni nadie pueda impedirlo. Es el delito de los derrotados. Alguien dijo que en estos casos "son los vencidos traidores, los vencedores leales". Muchos, y aun los más, esperarán circunstancias extraordinarias para que a los reos de delitos políticos se les aplique, en un clima de hipocresía y mentira, alguna gracia, si es que hasta allá se llega. Y acerca del sensible tema, que muchos evitan, quiero muy especialmente recordar las clásicas palabras de Rivarola cuando enfrentándose con el marco político del asunto, escribió: "Quizás deba en definitiva borrarse de los códigos penales una clase de delitos que son castigados solamente cuando sus autores no realizan su propósito y que son en cambio acciones altamente meritorias que obligan al reconocimiento de la posterioridad, cuando consiguen derrocar una tiranía, independizar un pueblo o perfeccionar una forma institucional. No podemos rememorar el pasado ni contemplar las estatuas de nuestras plazas públicas sin encontrar venerados como héroes a los autores de rebeliones, de sediciones y de motines" (Cfr. Valencia, 2007, pp. 342-343). delito político, conducta acaso inspirada en discutir la organización misma del Estado y sus instituciones fundamentales, las leyes o el gobierno, o en perturbar el libre funcionamiento del régimen constitucional y legal vigentes (rebelión, sedición, conspiración). Dicho por otros -y la opinión se extiende más cada día-, este era el tema en su propia raíz y en sus exactos cimientos. Sea como sea, hubimos de rehuir la discusión del delito político, porque tempranamente, y con claro distanciamiento, las posturas de la Sala Penal cerraron todo diálogo al descartar el examen del bien jurídico lesionado sin ocuparse de la causa política que de seguro inspiró la conducta de algunos de los parlamentarios acusados, por lo cual, los hechos se desnaturalizaron por completo y aquí todo terminó. El jurista, y más si es juez, no puede desatender las circunstancias especialísimas del momento y el entorno que lo rodea. He ahí el problema ${ }^{5}$. Advertimos todos, en fin, que la doctrina jurídica del delito político no se abordó con la cientificidad del caso, y no sé si porque habían otras preocupaciones dominantes, que de esta manera las cosas del derecho penal pasan a segundo plano. Pero todo no fue turbio ni enebroso en este proceso, si los delitos políticos se miran como son, avizorando el fin y los motivos de la acción.

Reflexionando en mi interior, he explicado en mis clases, con bastantes palabras, y no hay que ir a otra cosa, que el Estado y toda su raigambre republicana no se legitiman cuando los derechos fundamentales de los justiciables son hollados y dejados de lado y las normas superiores desconocidas en un sentido que los abogados no alcanzamos a comprender. No se edifica nada

5 Excelente y muy puesto en razón el estudio doctrinal del profesor Fernando Velásquez Velásquez, a propósito de esos asuntos. Clentíficamente honrado, muestra graves reparos a las actuaciones de la Sala Penal y a sus decisiones por ir en contravía del ordenamiento constitucional y legal. Reconforta saber que no todo está perdido en Colombia. (Vid., Delito político o delito común, Boletín 10 del Instituto de Estudios Constitucionales, Universidad Serglo Arboleda, Bogotá, agosto de 2007). 
perdurable sino sobre la sumisión al orden jurídico establecido y el acatamiento a la Carta. Apenas habrá argumentos para explicarlo.

El respeto inmenso que he tenido, desde siempre, por la Sala Penal de la Corte Suprema de Justicia, como institución y como cabeza del poder judicial, y por quienes la integran, no me permite, esta vez, aprobar o consentir los planteamientos jurídicos y legales expuestos por los señores magistrados que intervinieron en todas las actuaciones y trámites del proceso ${ }^{6}$, cuando los defensores, o al menos yo, hemos vivido en carne propia, de facto y de iure, el quebrantamiento, por acción u omisión, de las garantías fundamentales y prerrogativas que protegen a los ciudadanos dentro del marco de la legitimidad y el amparo de la Constitución?. Equi-

6 La Sala Penal de la Corte Suprema de Justicia organizó e integró un grupo de juristas auxiliares, verdaderamente crecido y difíci de superar, para investigar los procesos de los parlamentarios. A los nueve magistrados titulares se sumaron otros más -y está bien citado el adverbio de aumento-, para realizar la actividad judicial y ejecutar los procedimientos que el caso ameritaba. Por contraste, los congresistas apenas contaron con un sólo letrado, y acaso un suplente, para enfrentarse con la maquinaria estatal y todos sus elementos de acción. Bien que no importa el número ni el avasallamiento, cuando el defensor es capaz de decir con respeto y altura, con lealtad y con toda energía crítica, y si se quiere, con celo y altivez, sus reparos y observaciones, y a más de esto, mostrar, sin titubeos ni estrecheces, los yerros cometidos. Es el máximo deber del abogado, y escribo esto, con profunda emoción... que nosotros tenemos obligaciones, pero también derechos, sin que tengamos las manos atadas con una tosca cuerda, como en el dibujo de Montessi. Hay que salvar la ley y la dignidad de los penalistas de Colombia, pero mientras tanto, todo sigue igual.

$7 \mathrm{Y}$ aunque todo esté escrito y dicho en nuestros memoriales, alzo la voz para pedirle al Congreso Nacional que presente una reforma a la Carta, en orden a consagrar, a más del principio de la doble instancia que no es un derecho de quinta categoría (sigo creyendo en su validez jurídica dentro del ordenamiento colombiano), la realidad de una norma superior que diga y exprese, que en las causas que se sigan contra los parlamentarios, sólo podrá detenérselos, cuando se produzca Ilamamiento a juicio en firme, y además, se les levante el fuero por la Cámara respectiva. Esto no necesita explicación, conociendo los antecedentes de las capturas que se armaron contra los congresistas, para producir una verdadera función mediática, que como en el circo, tiene de todo, sin que falte, por supuesto, el impresionante espectáculo de variedades, para atraer la atención pública. Es que no le veo sentido a la aparatosa, como insensible, manera de aprehensión que emplearon algunos funcionarios de la Fiscalía General de la Nación contra aquellos, sin respetar su propia dignidad personal y la de su familia, su condición de seres humanos. Y como aquí no se revelan palabras vacías, fue muy de lamentar $-\mathrm{y}$ no quiero denostar por vocado o no, pienso así, de igual manera que el ignorado del evangelio a quien nadie quiso tratar ni conocer. Los enumero en desorden: violación al principio de la doble instancia, reproche dirigido a todo el Estado colombiano; vulneración a las reglas de inmediación que hacen al principio del juez natural para presidir personalmente los señores magistrados titulares la diligencia de indagatoria y las pruebas que se practican en su sede; negación al estado de libertad dentro del proceso; incomprensión dogmática por el delito, tipo de concierto para delinquir agravado, cuando la lógica de los hechos tiende a registrar la comisión de delitos políticos; conculcación al derecho de defensa, a las garantías del imputado y al debido proceso; silencio absoluto a cardinales problemas dogmáticos planteados por la defensa (entre otros, indefinición de los delitos de peligro, falta de especificación de los coautores en el delito de concierto para delinquir y en las conductas que atentan contra la participación democrática); desconocimiento de las reglas de la sana crítica al otorgar la Sala Penal plena y absoluta credibilidad a testimonios que nunca debieron merecer los calificativos otorgados; ausencia de análisis, o mejor de motivación, a los problemas propios, a los temas electorales y de votación planteados por la defensa; inaplicación al artículo 308 del C. de P. P., texto legal vigente para el momento de los hechos; incapacidad jurídica del defensor para entender las tesis de extemporaneidad y superfluidad alegadas por la Corte, jurisprudencia que lesiona los verdaderos alcances del sistema republicano que nos rige y tantas cosas más que abruman, si sigo pensando

mi cuenta-, que a mi defendido se le aprehendiera en su casa, frente a sus pequeños hijos, con el daño espiritual y psicológico que ello contiene para siempre. Todo esto es decepcionante. Por qué no se piensa en citarlos primero ante el Presidente de la Corte Suprema de Justicia o de la Sala Penal, para que se sometan voluntariamente a la jurisdicción, y sólo en caso de renuencia, proceder de inmediato a su captura. Debemos desde ya pensar, y con cálculo razonado lo digo, en un "derecho penal del ciudadano" que derrote los excesos y arbitrariedades del poder estatal, porque el derecho en función de la justicia aún existe. Los valores humanos, y excepcionalmente las jerarquías, deben siempre acatarse. 
en estos asuntos tan poblados de interrogantes y problemas no aclarados. Inspirándome en Voltaire digo, sin ambages ni rebozos, que es peligroso tener razón cuando los jueces están equivocados. Por siempre lo será.

\begin{abstract}
Entenderán todos que el derecho a opinar se ejerce nada más que por principios, así sea para reivindicar, las reglas del sistema positivo -en el cual muchos ya no creen, yo incluido-, y para reclamar, porque hace falta, por los pilares normativos que tienen su origen en la ley fundamental. Menos mal que a nadie se condena por sus ideas, ni por delito de pensamiento. Como yo no transijo nunca con nada que afecte la libertad para expresar las razones -hay que amar la libertad con idolatría, y acaso con pasión-, he dicho y explicado, lo que creo de mi resorte decir y explicar, que éste ha sido y será mi auténtico destino. Mi padre me enseñó, sin llevarse el mundo por delante, que las cosas o son blancas o son negras, nunca grises, $y$ bien es verdad que nunca he sido inferior a estos postulados porque siempre hay que tener correspondencia entre el juicio y la acción. Me acuerdo de Maura: Mis obras no irán jamás en dirección contraria a mis palabras; porque cuando el hombre hace una cosa y dice otra, es un histrión y para ese oficio no tengo yo aptitudes.
\end{abstract}

Aquí se muestran algunos documentos y los pliegos jurídicos que hablan por sí solos, y se conservan en pie, las discordancias y las diferencias que se dejaron sentir en su momento, a las que habrá que añadir otras muchas, si es que hasta allá se llega. No he borrado una sola línea de lo que entonces apunté, salvo por supuesto, los errores tipográficos y los lapus cálami, que nunca faltan, cuando se trata de exponer raciocinios y sentimientos. Claro está, y no lo descarto, que la perspectiva personal puede anublar y estrechar la sindéresis y la lógica del abogado, y por eso está bien, y además se torna imperioso, que se conozcan los argumentos de parte y parte, para que, quienes se acerquen a estos asuntos, extraigan las conclusiones y las consecuencias jurídicas de rigor. Creo que venturosamente hay en Colombia más derecho penal del que algunos suponen.

\section{DE LA JURISPRUDENCIA A LA JURISPRUDENCIA. SU VALOR NORMATIVO. PROHIBICIÓN DE LA RETROACTIVIDAD DESFAVORABLE}

\section{Dentro de los confines lógicos y jurídicos de estos conocimientos, digamos}

a. La jurisprudencia, para iniciarnos en sus ritos, no es eterna ni inmutable, y no ha de durar para siempre en el espacio de lo infinito. Nunca permanece estacionaria y bien se entiende que los magistrados no han de seguir las pisadas de sus antecesores, de considerar que la vieja interpretación se ha formado contra legem. Un cambio de jurisprudencia -que los jueces supremos deben saber utilizar- es posible dentro de la propia cultura jurídica, cuando razones de peso y alcances relevantes que responden a nuevas necesidades y matices, jurídicos, sociales o de otro orden, presionan en este oriente por ser necesarias para la justa solución del caso enjuiciado, precedente que, acomodado al cambio de las nuevas circunstancias, operará en lo venidero.

b. La jurisprudencia -de acuerdo con una concepción clásica que conocen juristas y profanosrige siempre hacia el futuro $y$ ha de aplicarse en estrecha vinculación con los hechos del proceso, conforme a la ley vigente en el momento de la comisión del delito, y lo propio, en relación con otras situaciones de parecido tenor. El valor educativo de la jurisprudencia no puede estar sometido a proclamar lo insostenible, ni a ungir razones distintas al respeto $y$ protección del individuo frente al poder penal del Estado, cualquiera sea la forma política del Establecimiento.

c. La interpretación oficial y su actividad intelectual que enlazan tan íntimamente -como dirían 
los jurisconsultos romanos- la teoría y práctica del derecho han de adaptarse solamente a supuestos análogos, o idénticos, o parecidos a los que los motivaron (jurisprudencia constante: auctoritas rerum perpetuo similiter indicatarum). Importa destacar -y es una opinión bien fundada- que los fallos que sientan la sabiduría del derecho se imponen para lo sucesivo ${ }^{8}$.

d. Una jurisprudencia razonable será aquella que acatando el derecho a la legalidad penal, con vocación garantista interpreta y aplica la ley sin forzar su recto sentido, ni distorsionar las perspectivas democráticas, ni vulnerar los principios constitucionales. Mentalidad viva de lo jurídico bajo el imperio de la ley y el saber penal. No lo será, cuando los jueces que se arrogan un poder de interpretación -que no se sabe cómo Ilamarlo-, modifican el acto puro de la actividad judicial para crear un espacio de incertidumbre e inseguridad en sentido agravatorio, más allá de lo fijado por las leyes. No se reivindica la prudentia iuris cuando se atenta contra el sentido de la ley misma, o cuando se acomoda a un caso y no a otro similar, o cuando el poder de los magistrados le imprime, con un sello absoluto, carácter retroactivo al naciente criterio jurisprudencial. No hay aquí una "interpretación escrupulosa", como exclamaría Kelsen al examinar la metamorfosis de la idea de justicia. Y aún se ha dicho que ante las variaciones en la composición personal del órgano judicial, esto debe considerarse como un rasgo patológico que debe corregirse a toda costa (Ferreres Camella, 2002, p. 170). El oficio intelectual, agregamos, nunca puede ser una aventura.

e. La realización de lo que es justo o injusto tiene una estima decisiva e importante en el valor de la jurisprudencia. No hay, no puede haber, ilación entre ésta y la realización del derecho, cuando los jueces asumen o adoptan posturas

8 Teófilo de Buen, Introducción al Estudio del Derecho Civil, Editorial Revista de Derecho Privado, Madrid, 1932, p. 326. extrañas al objeto propio de la situación enjuiciada y al saber jurídico, contrariando la confianza -que no se puede defraudar-, que el ciudadano tiene en la ley y en la autoridad de las sentencias que hayan sido siempre las mismas, como dice el Digesto (Ley 38, Título. 3, Libro. 1). Por eso se destaca su valor jurídico como sentencia.

f. Si los destinatarios de la ley penal tienen derecho a que las conductas por ellos cometidas figuren en un sistema en el que se garantice la irretroactividad de las disposiciones sancionadoras no favorables o restrictivas de sus derechos, razonando a fortiori, a esos mismos ciudadanos debe asistirles el derecho a que la jurisprudencia que se vincula a su situación personal quede igualmente determinada, con el uso interpretativo judicial que se fija en hipótesis similares, "sin ningún pretexto de celo o bien público", como diría Cesare Bonesana, Marqués de Beccaria.

g. Una cosa es que la jurisprudencia exista al momento de la comisión del delito, y se proyecte contemporáneamente al caso bajo examen por acomodarse a lo que se decide, y otra muy distinta, que la modificación jurisprudencial tenga efectos retroactivos, lo que envuelve una lesión a la garantía constitucional de la irretroactividad penal. Lo razonable es sinónimo de justo, equilibrado, sensato, prudente y racional. No exagerado, o falto de equidad, ni aplicado a cosas imposibles. Es interpretar la ley, sin distorsiones ni esguinces, quedando circunscrita al tiempo durante el cual rige, o está en vigor, rechazando una nueva interpretación adversa al imputado. Lo irrazonable, es lo otro ${ }^{9}$.

h. Siguiendo la doctrina española, tratar los cambios legislativos de manera distinta a los cambios jurisprudenciales no parece que esté justificado, dados los valores de la seguridad

9 No somos partidarios de la libre jurisprudencia, del arbitrio judicial saltando por encima de la ley con quebranto de la seguridad jurídica, fin primordial del derecho en general y muy particularmente del penal (Oneca, 1986, p. 115). 
jurídica y la imparcialidad. Sería irónico que, por querer respetar ciertos dogmas jurídicos originados en la Revolución Francesa, nos negáramos hoy a proyectar sobre la jurisprudencia la regla que impide la retroactividad desfavorable. Y sería irónico porque los revolucionarios franceses atribuyeron una importancia normativa de primer orden a la interpretación de las leyes, hasta el punto de que consideraron que sólo el Parlamento podía interpretar, debiendo los jueces elevarle una consulta en caso de duda. Si hoy los tribunales interpretan según su propio juicio, sin remitir la duda al Parlamento, sería ilógico desconocer entonces el impacto normativo que pueden provocar con un cambio jurisprudencial (Ferreres Camella, p. 197).

i. Colmaría nuestro asombro -bien que al presente ya no me pasmo, ni me maravillo, ni me espanto de nada, porque veo los efectos y no ignoro las causas-, que se pretendiera dar carácter retroactivo a la jurisprudencia penal, y esto, en los casos particulares de los parlamentarios, porque nunca antes -lo cual tiene el encanto de lo imprevisto-, se había planteado tamaña novedad, que envuelve una excepcional demudación. Bien apunta la doctrina: Si el cambio es desfavorable para el reo, icómo garantizar que el tribunal cambia el criterio, no para perjudicar al acusado que tiene enfrente, sino para sentar una nueva regla, más ajustada a Derecho? La respuesta es sencilla: estableciendo que el cambio sólo producirá efectos prospectivos. Se absolverá al acusado, pero se fijará ya una nueva interpretación, que será aplicable en el futuro. Así pues, tanto desde el punto de vista de la seguridad jurídica, como bajo el prisma de la imparcialidad, hay razones para defender la tesis de que los cambios jurisprudenciales desfavorables al reo no pueden tener efectos retroactivos (Ferreres Camella, pp. 195-196). j. Del mayor interés recordar que en principios generales, no sólo la jurisprudencia obligatoria es inconstitucional, sino también la retroactividad jurisprudencial más gravosa. Diversos autores, con dejo de aliento y profunda observación, se han hecho eco del anterior punto de vista. Citemos a Enrique Bacigalupo (pp. 105 y ss.): “Un Estado de Derecho, es aquel en que los ciudadanos pueden calcular anticipadamente que ocurrirá en el futuro en un sentido específico"; es decir: cómo se comportarán otros individuos y como lo hará el Estado, sobre todo como garante de la eficacia del derecho... La seguridad jurídica dentro del Estado requiere que todo ciudadano, pueda prever, conociendo el orden normativo, la actuación de los órganos estatales $y$, especialmente, la de los jurisdiccionales, dentro del ámbito territorial del Estado, concluyendo que de lo contrario, no se puede hablar de un Estado y de un orden jurídico. Ofreciendo una definición de jurisprudencia, la describe Julio B. Maier (2002, p. 128) -el eximio procesalista argentino-, como la reunión de decisiones concretas de los tribunales sobre casos que le son presentados, las cuales, unas veces por la repetición regular del fundamento normativo en que apoyan la solución de casos similares y otras por la posición jerárquica y la función que cumple en la organización judicial el mismo órgano que decide, permiten identificar una proposición jurídica sobre la vigencia de determinada regla jurídica, o sobre su significado o sobre el significado de sus elementos componentes, que se puede aplicar en el futuro a casos análogos, con cuyo pensamiento descartan la retroactividad. Todo lo demás importa un agravio constitucional.

k. Ocurre también que un sector de la doctrina entiende -atacando el problema desde una perspectiva distinta-, que debe permitirse al acusado alegar un error de prohibición invencible. Se pronuncia así, Bacigalupo, Juez del Tribunal Supremo de España (1983, p. 86). Y 
también Zaffaroni al apuntar que cuando una acción que hasta ese momento era considerada lícita pasa a ser tratada como ilícita en razón de un nuevo criterio interpretativo no puede serle reprochada al agente, porque eso equivaldría a pretender no sólo que los habitantes deban abstenerse de lo que la jurisprudencia considera legalmente prohibido, sino también todo lo que podría llegar a considerar prohibido en función de posibles criterios interpretativos. No se trata de una cuestión de legalidad ni de tipicidad, dice el magistrado argentino, sino de una cuestión de culpabilidad, que debe plantearse como error de prohibición invencible... ¡Para pensarlo, que ya es bastante...!

I. Surge entonces, en este tópico, una gravísima cuestión de principios por afectar la seguridad jurídica $^{10}$, la igualdad, la imparcialidad" $\mathrm{y}$ la garantía de la irretroactividad del derecho penal. En este punto no cabe duda alguna que la jurisprudencia se ensancha y amplía de tal manera

10 La seguridad jurídica sigue presionando en contra de la retroactividad: aunque la nueva interpretación exprese verdaderamente el Derecho preexistente, lo cierto es que el tribunal encargado de formar jurisprudencia había consagrado en el pasado una interpretación distinta. Y la protección de la imparcialidad exige que se pongan límites a ese tribunal: aunque el tribunal diga que cambia de interpretación porque la anterior era errónea, no deja de existir el riesgo de que el cambio obedezca en realidad al uso arbitrario de su poder interpretativo, en perjuicio de una de las partes. Cabría sostener que, mientras que el argumento de la seguridad jurídica exige que no se pueda aplicar el nuevo criterio jurisprudencial a las personas que realizaron los hechos con anterioridad a que el tribunal fijara el nuevo criterio, el argumento de la imparcialidad, en cambio, sólo exige que el nuevo criterio no se aplique en el caso concreto en el que se establece por primera vez. (Ferreres Camella, p. 196).

11 A mi juicio -apunta Víctor Ferreres Camella-, debería entenderse que las variaciones jurisprudenciales desfavorables para el reo sólo producen efectos con respecto a los hechos acaecidos con posterioridad al cambio. La inaplicabilidad a los hechos anteriores se funda en las mismas razones de seguridad jurídica y de protección de la imparcialidad (igualdad) que inspiran la prohibición constitucional de la retroactividad de las disposiciones sancionadoras desfavorables (art. 9.3 de la CE). En efecto, desde el punto de vista de la seguridad jurídica, la equiparación entre ley y jurisprudencia parece obligada. Si la seguridad jurídica padece cuando el legislador ejercita su competencia normativa promulgando con efectos retroactivos un nuevo texto más perjudicial para el reo, también queda afectada negativamente cuando es el juez quien, en uso de su poder interpretativo, sustituye, con efectos retroactivos, el criterio establecido hasta entonces por otro más desfavorable. (Ferreres Comella, p. 194). que asume la potestad legislativa, y por eso, los riesgos aumentan "porque el Juez conoce perfectamente a los afectados por sus inter. pretaciones (los tiene prácticamente en frente, esperando la resolución judicial)"12. Añadimos nosotros, que de ahora en adelante se hablará para llamar a las cosas por su verdadero nombre, no de jueces -magistrados, sino de jueces-legisladores. Éstos y no otros son los términos de la cuestión. En lo demás, hagamos constar que ese mandato normativo no se los ha atribuido ningún precepto del derecho positivo ${ }^{13}$.

m. En suma, según lo advertido: la prohibición constitucional de la irretroactividad penal se extenderá también a las mudanzas jurisprudenciales desfavorables para el acusado. La juris. prudencia de que nos ocupamos únicamente debe considerarse en los casos del mañana, pro futuro ${ }^{14} \mathrm{y}$ en los procesos en curso. Lo contrario significaría castigar al individuo por su confianza en el derecho.

2. En lo demás, no he encontrado ninguna página en los 120 años de existencia de la Sala Penal de Casación -y a mí me gusta el polvo de archivos y bibliotecas-, que en el pujo de su poderosa ideación, la Corte Suprema de Justicia -guardiana emblemática de la juricidad y el derechohubiera contemplado, con la excepción de que se pretende ahora, un cambio jurisprudencial desfavorable al acusado. Parafraseando a Menéndez Pelayo tendré que repetir, a mi modo, que "cuando Dios quiere castigar a una nación, la puebla de jurisprudencia altiva, autoritaria, sin autolimitación ni control a lo predeterminado,

12 Así, Ferreres Comella, (p. 195).

13 Sostiene el profesor Fulgencio Madrid Conesa, que "si se plante el problema del efecto de los cambios jurisprudenciales, es básicamente porque el legislador no ha respetado el principio de taxatividad $y$ ha atribuido a los jueces un poder normativo de que deberían carecer" (Universidad de Valencia, 1982).

14 El Tribunal Supremo Español -históricamente respetuoso de los valores democráticos de legitimidad del Derecho y del Estadose identifica con este punto de vista. Véanse, entre otras, las sentencias de la Sala $2^{\mathrm{a}}$, de 11 de mayo de 1994, de 13 de abr de 1998, de 20 de marzo de 1998 y de 20 de julio de 2001. 
a la certeza jurídica y a la seguridad política de los ciudadanos, y además, retroactiva". Cobra aquí importancia la frase de D’Ors cuando refiriéndose a las manifestaciones de la jurisprudencia que están en franca contradicción con el Derecho, y a las decisiones judiciales injustas, decía que "detrás del juez hay que ver siempre al jurisprudente que le inspira"15 Está dicho todo. Resulta inevitable afirmar, por último, que es de extrañar que nuestros juristas, escritores y profesores -a quienes no les alcanza ninguna disculpa-, no digan nada y guarden silencio, porque ahora nadie tiene opinión ni voluntad para ir en contra de la tesis del cambio jurisprudencial retroactivo. Se ha perdido el espíritu crítico y los fueros de la independencia. ¡Esto no debe ser así, pero es así!

\section{EL CAREO: LAS COSAS TIENEN SU HISTORIA}

3. El careo es un medio de prueba, y en lo esencial, una confrontación que sirve para despejar, con un enfrentamiento entre el acusado y los testigos de cargo que declaran en su contra, las dudas provenientes de sus exposiciones. Trátase -como dice la doctrina-, de un derecho constitucional de la defensa del inculpado en el proceso penal (Fix-Zamudio, 1993, pp. 416 y 417). El careo, cuanto a su naturaleza potestativa y residual, compete de modo discrecional al funcionario de turno, pero también a las partes, cuando surge la necesidad de su realización. Perfectamente recuerdo que en el año de 1995 el doctor Edgar Saavedra Rojas, y quien esto escribe, defendimos ante la Sala Penal de la Corte Suprema de Justicia en nuestra condición de magistrados (Cas. 19 de mayo de 1995), su reconocimiento o validez en la legislación procesal penal colombiana con estribo en preceptos legales de mayor jerarquía, cuales son,

15 De la "Prudencia iuris" a la Jurisprudencia del Tribunal Supremo en Información Jurídica, 1974, p. 3. las normas aprobatorias de los tratados internacionales frente a las leyes ordinarias. Dentro de un apretado tejido de notas y observaciones -que dieron fe del estado de las cosas-, fuimos finalmente derrotados, al punto que la verdad de la mayoría quedó a salvo. Miro con interés, que al menos en la escritura, la actual Sala Penal de la Corte Suprema de Justicia regrese en esta escala de apreciaciones a creencias anteriores disidentes, lo que confirma, y la idea es exacta, que en el mundo judicial, y también en el otro, nada es definitivo y absoluto, como tengo de esto larga noticia ${ }^{16}$.

16 La garantía del careo constitucional -enseña con bastante motivo la doctrina mexicana-, está prevista en la fracción IV, del apartado A, del artículo 20 constitucional hasta el día de hoy; en la reforma actual, dicha garantía fue suprimida, al parecer sin explicación alguna; considero que dicha desaparición es lamentable; sin embargo, la figura del careo está expresamente proclamada en los tratados internacionales que México firmó y ratificó; por lo que si bien dicha garantía fue eliminada del texto constitucional, sigue siendo de observancia obligatoria para México, y podrá y deberá ser exigida de conformidad con los tratados internacionales antes mencionados; amén de que podrá ser exigida por lo que hace a la garantía del debido proceso (Hernández-Romo Valencia, 2009, pp. 150-151). No cabe duda de que se está en lo cierto. Exactamente lo mismo que sostuvimos con el doctor Saavedra, catorce años atrás, con razones jurídicamente significativas, bien que será para otro día tratar más extensamente esto, para llevar las cosas a su propio sitio. Todavía queda por decir que se quita todo mérito al derecho a carearse cuando los jueces impiden al acusado cuestionar a quien depone en su contra para poner de manifiesto que el testigo de cargo está mintiendo o está equivocado. No hay aquí una verdadera oportunidad de defensa. Recuerda el autor citado -refiriéndose a los antecedentes históricos del careo-, que en el libro de los Hechos de los Apóstoles, cuando el gobernador Festo, discutiendo sobre cuál era el tratamiento adecuado del prisionero Pablo, dijo: "No es costumbre de los romanos entregar a un acusado antes de que pueda carearse con sus acusadores y tener la oportunidad de defenderse contra los cargos". Espléndido pensamiento y expresiones sobremanera sensatas y prudentes que jamás por jamás deberán olvidarse. $Y$ tiene razón el escritor en antes citado -es mío el arcaísmo-, cuando se ha creído en la necesidad de recomendar la lectura de las obras de Fitzmyer y de Kursinger. Dice el primero: "La respuesta de Festo implícitamente contrasta los procedimientos judíos con los romanos. Insiste en la aequita romana, la tradicional imparcialidad romana, pues desde el punto de vista romano no se ha demostrado la culpabilidad de Pablo. No se toleraban las acusaciones anónimas, y los querellantes tenían que carearse con el acusado ante el juez". Y en igual sentido, apunta el segundo: ".... A los cuales respondí que no es costumbre entre los romanos entregar a ningún hombre sin que previamente el acusado tenga delante a los acusadores y se le dé la oportunidad para defenderse de la acusación" (p. 153). Me parece importante agregar que en los clásicos criterios de los jurisconsultos que forjaron el ius romanum nunca apareció el asunto de la superflulidad, ahora en boga. 


\section{PARA LEER MÁS. DE NUEVO LA SUPERFLUIDAD}

4. En un caso que yo conocí, por ser pertinente, y además, por ser probanza de excepcional valor para demostrar la impostura y el artificio del declarante, solicitó el abogado de la defensa una diligencia de confrontación entre el "testigo" $y$ el imputado. Ordenada ésta e iniciada, tuvo que suspenderse porque el acreditado testigo se negó a intervenir en ella. Para evidenciar su mala intención, y que es reveladora, insistió la defensa en que se continuara la confrontación porque tenía todas las ventajas y ninguno de los inconvenientes para destruir los cargos y rechazar sus acriminaciones. Tildó la Sala Penal de Casación de "superflua" (??) la solicitud elevada por el defensor para seguir y terminar lo comenzado, lo que ofrece apenas sentido ${ }^{17}$. Con criterios que a mí me parecieron juiciosos, y de pronto no lo fueron, pero vale la pena que se conozcan, replicó el letrado lo siguiente:

\begin{abstract}
Sigo sin entender por qué se tilda de superflua la continuación de la diligencia de careo entre y el acusado? No es éste, acaso, un derecho que tiene el inculpado para rebatir la maldad y la malicia del declarante, lo que le hubiera permitido al sindicado desenmascarar al farsante, y probar de una vez por todas, su estado de inocencia, diligencia cuya validez y alcance, en abstracto, hace poco resaltó en un proceso penal y con todos los merecimientos jurídicos, la Sala Penal de la Corte? ¿Será que la confrontación tiene valor en unos casos y en otros no? ¿Entonces, por qué se tilda de superflua la práctica de tan esencial probanza, cuando es todo lo contrario? De la misma manera se solicitó a la Corte hacer todos los esfuerzos posibles por traer a los autos la declaración de alias B, por cuanto que la Fiscalía General de la Nación, según informaron los medios, pudo contactarlo en la ciudad de Miami, elemento probatorio de extraordinaria
\end{abstract}

17 A manera de constancia escribí entonces, $y$ hoy lo reafirmo. trascendencia para el acusado, pero la Sala dijo que esa prueba era superflua, en el sentido que ya se conoce, de que no era necesaria, que está demás, con lo cual, la misma Corte contribuye de alguna manera a la propia incriminación del acusado. Esto no puede ser así, porque deja bastante que desear por lo irreal e incomprensible del razonamiento, que es lo mismo. Puede tildar la Sala Penal de la Corte de superfluas todas estas probanzas, y todas las demás presentadas por la defensa, pero no podrá dejar de ver, cuando medite mejor estos temas, que con estas actitudes se han vulnerado de manera especialmente grave los derechos mismos del acusado, como si éste asumiera un papel del todo pasivo, criterio que no se corresponde con la fórmula terminante de la inviolabilidad de la defensa, que también tiene lo suyo, frente al poder penal del Estado. Se dejaron de lado los atributos del debido proceso, la igualdad de armas, el derecho de defensa y todas las garantías fundamentales, derechos inalienables de la persona y anteriores al Estado mismo. Desengañado estoy de estas cosas, bien que me reconforta saber que el derecho, la juridicidad y la justicia no mueren jamás, no obstante que en veces pienso, acaso con razón pero con desánimo, con Jiménez de Asúa, que mejor es volver a nuestras vocaciones primarias: la ciencia y la cátedra (Memorial de junio 28 de 2007, p. 36. Rad. 26.470).

5. Cierto es que nuestros alegatos no se ven ni se sienten, pero sabemos que existen..., porque los vemos impresos y estampados, por decirlo de un modo gráfico, aunque se piense que su valor sea ninguno. De suerte que, entre las ideas y entre las realidades, preocupa el sentido de aquella interpretación. La superfluidad sentó sus reales en los discursos judiciales rasa y lisa como la palma de la mano, o si se prefiere, como el agua entre las manos. L0 escribo así, diciendo las cuatro verdades a la luz de la disserandi ratio. Hablo de esto pol alguna experiencia y algún conocer jurídico que a veces de nada sirven, porque hoy todo se ve
(

ESC

En la

ellas

la $p r$

renci

losh

toda:

pers

do $S$

la $m$

simp

nunc

teza,

de la

indo

la $m$

judic

versá

nues

Por I

de in

cion.

del p

vapu

discí

gara

pena

$y$ rec

filos

todo.

tantc

dent

18 
con distancia y desapego, y esto es lo único cierto. iLa vida del abogado que defiende a un congresista en un juicio es muy triste!

\section{ESCRITOS SIN RESPUESTA}

En las notas que siguen $-y$ no obstante que en ellas palpita una intensa preocupación acerca de la presunción de inocencia y de la extraña injerencia de los medios para juzgar la conducta de los hombres, y de la intromisión de veedurías, con todas sus inevitables quejas y censuras-, debe perseverar la idea de que Colombia es un Estado Social de Derecho y que nadie puede invadir la majestad de la justicia, con procedimientos simples y expeditos y con prevenciones de nunca acabar. El progreso del derecho, la certeza, la seguridad jurídica y la recta aplicación de la ley están reservadas a las instituciones de indole jurisdiccional y a nadie más. Es obligante la marginación de individuos extraños al poder judicial, aunque aquí las cosas ocurren en viceversa, preocupante y terrible argumento que en nuestro país goza de inmenso prestigio.

Por lo demás, y ante el irrespeto de la presunción de inocencia, principio elevado a rango constitucional y que es una de las grandes cuestiones del proceso penal, me he sentido tan herido $y$ vapuleado, que no sé ya que enseñarles a mis discípulos. O que se trata de apasionantes reglas o garantías del ciudadano sometido a un proceso penal, mientras éste dure en todas sus instancias $y$ recursos $^{18}$. O que no se debe creer ya en su filosofía y en sus postulados, porque al presente, todos los que posan de juristas y los que no son tanto, jamás los respetan y todos lo pisotean, dentro de una auténtica arbitrariedad sistemática

18 Principios que se levantaron a partir del movimiento filosófico iniciado en el siglo XVIII, incorporados a la Declaración de los Derechos del Hombre y del Ciudadano de 1789, recogidos después en la Revolución Francesa. El artículo 9 adoctrinaba: "A ningún hombre puede llamársele reo antes de la sentencia del juez y la sociedad no puede retirarle la protección pública sino cuando queda sentenciado que él violó los pactos bajo las cuales fue aceptado en sociedad" (Beccaria). e institucional, como así lo ha enseñado la historia pública de este país. Los presuntos culpables son culpables, y punto, que aquí entra lo peregrino, por encima de la verdad procesal penal. No puede ser esta la grande idea de los tiempos actuales, ni la fórmula de nuestra generación, como los hechos han demostrado, de una u otra manera. Y como no se ven aquí reductos de coherencia, ni lo esencial del ideario constitucional, porque hay mucho más, mejor será irradiar de nuestra Carta el dicho principio, en razón a que están en crisis las concepciones liberales al existir una nueva legalidad republicana sin que sea preciso explicarlo más claro. ¿Es éste el porvenir que nos espera? Lo siento, pero no lo encuentro razonable ni lógico.

\section{REFERENCIAS}

Bacigalupo, E. (1983). Principios de Derecho Penal, Parte General, Madrid: Ediciones Akal.

Bacigalupo. E. Hacia el nuevo Derecho penal, Hammurabi, Vid. Capítulo IV.

Ferreres Camella, V. (2002). El principio de taxatividad en materia penal y el valor normativo de la jurisprudencia, una perspectiva constitucional. Madrid: Ediciones Civitas.

Fix-Zamudio, H. (1993). Diccionario Jurídico Mexicano, T.1. (6 $6^{\mathrm{a}}$ ed.). México: Editorial Porrúa.

Hernández-Romo Valencia, P. (2009). Las garantías del inculpado. México: Editorial Porrúa, Universidad Panamericana.

Maier, J.B. (2002). Derecho Procesal Penal, fundamentos. T. 1, (2 ${ }^{\mathrm{a}}$. ed.). Buenos Aires: Editores del Puerto. 2a reimpresión.

Oneca, J.A. (1986). Derecho Penal. (2 a ed.). Madrid: Ediciones Akal. 
Sociedad Anónima Editora, Comercial, Industrial y Financiera. (2003). Defensa de la Constitución, Buenos Aires.

Teófilo de Buen. (1932). Introducción al Estudio del Derecho Civil. Editorial Revista de Derecho Privado, Madrid.
Valencia M., J.E. (2007). Derecho Penal Colombiano. Parte Especial. T.1. Bogotá: Ediciones.

Zannoni, E. \& Bíscaro, B. (1993). Responsabilidad de los medios de prensa. Buenos Aires. 